\title{
Shoshichi during Nozawa Middle School Days
}

\section{by Noboru Naito}

My heartfelt condolence for the sudden demise of Professor Shoshichi Kobayashi. May his soul rest in peace. I had the privilege to spend 2 years and 9 months as a classmate of Shoshichi in the middle school. I will recollect what the middle school in Shinshu (Nagano Prefecture) was like towards the end of World War II, and will record my memory of this gifted friend who flourished his talent, despite the hardship he had as an evacuee.

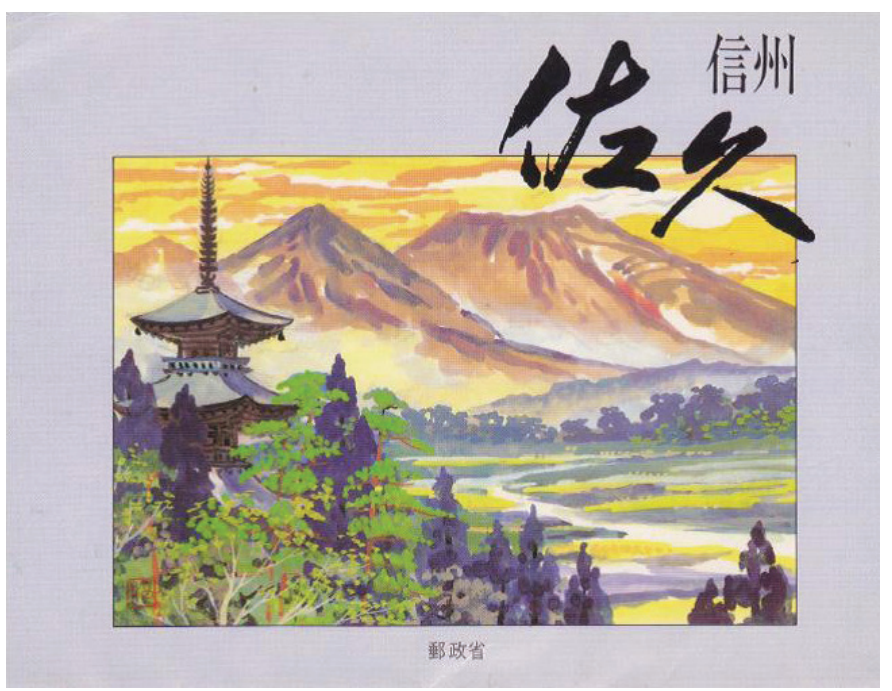

"The evening glow of the Saku Plain" by Kimito Suzuki (1928-)

\section{The Kobayashi Family at Minamisaku, Nagano}

Shoshichi was raised in Tokyo, but in early 1945 his family moved first to Kofu-City, his parents hometown in order to avoid air raids in Tokyo. But Kofu became also unsafe, and in May 1945, the family moved to Hiraga Village in Minami-Saku, which is the east end of Shinshu (Nagano Prefecture) near the boundary of Gumma Prefecture. The family stayed in an annex of Mr. Kinjiro Yanagisawas house. ${ }^{1}$ Soon after the war ended the Koba-

\footnotetext{
${ }^{1}$ Mr. Naoyuki Yanagisawa (2nd son of Mr. Kinjiro Yanagisawa) and I were in the same class at Hiraga Elementary School. Mr. Nobuyoshi Yanagisawa (4th son of Kinjiro) who attended the Memorial Reception of May 25 was in the same class as Hisashi (Shoshichi's brother) at Hiraga Elementary School. Mr. Tadaharu (3rd son of Kinjiro) was in the same class as Toshinori (Shoshichi's brother).
}

yashi family stayed in the public hall of the village for a short while, and then moved to a detached house on the premise of Mr. Kesazo Yanagisawas house ${ }^{2}$.

Shoshichi was enrolled in Nozawa Middle School. The School had the rule which said that those who lived farther than $4 \mathrm{~km}$ in direct distance from the School were permitted to commute by bicycle. Shoshichi, whose distance is a bit short of this threshold, walked to the school spending about 40 minutes. ${ }^{3}$ My house was in Araya towards Nakagomi. It also took me about forty minutes to walk to the school. We put gaiters (puttees) around legs, carrying a rucksack (knapsack), and wearing a school cap. When I entered Nozawa Middle School in 1944, students in each district walked to the school in a group, forming a line as in military, with seniors at the head. But all seniors were taken to labor services by the spring of 1945 , so we commuted to the school with just friends.

\section{Nozawa Middle School During the War}

Owing to the "Ordinance of Secondary School" proclaimed in January 1943, and the "Middle School Regulation" enacted in March 1943, the course of study at Middle School was changed to four years and this rule was supposed to become in effect from the entering class of 1943. But the plan was accelerated so that the fourth year students who entered in April 1941 were scheduled to graduate in March 1945 together with the fifth year students so that they could join the workforce to carry out the War as early as possible.

\footnotetext{
${ }^{2}$ Mrs. Kiyoko Yamakawa who was also present at the Memorial Reception is the 4th daughter of Mr. Kesazo Yanagisawa. She kindly provided the above photo of the detached house on the same premise, where the Kobayashis stayed in 1947-48.

${ }^{3}$ In the south of their house, there was Uchiyama River, flowing from the border with Gumma Prefecture towards the west. If we cross Goka Bridge over the river and goes south for a while, we will hit Highway 254, which connects Tomioka, Gumma and Nozawa. On the immediate east of this corner was the center of Hiraga Village, where the village office, agricultural cooperative, ordinary and higher elementary schools, the post office, etc. were located. Shoshichi's route to the School was to go south in the northern side of Uchiyama River, cross Himura Bridge, turn to right, cross Tagogawa Bridge on the west, cross Koumi RailRoad to Nakagomi Station, and then cross Nozawa Bridge over Chikuma River to get to Nozawa Middle School. It took him about 40 minutes on foot.

The Saku Plain, as shown in the painting by Mr. Kimito Suzuki, is a land of picturesque scenary, with Mt. Asama (volcano) soaring in the north: in the south is Mt. Yatsugatake, and with a distant view of the Hida mountain range (or North Alps) in the west.
} 
Shinshu (or Nagano), in the mountainous country, had been thought foreign to air raids, but air-raid sirens became frequent, days and nights, and it was rumored that B29 bombers which had been increasingly coming with roaring noise might soon drop torpedoes in Naoetsu and Niigata Harbors. Large trucks began to travel to the north,

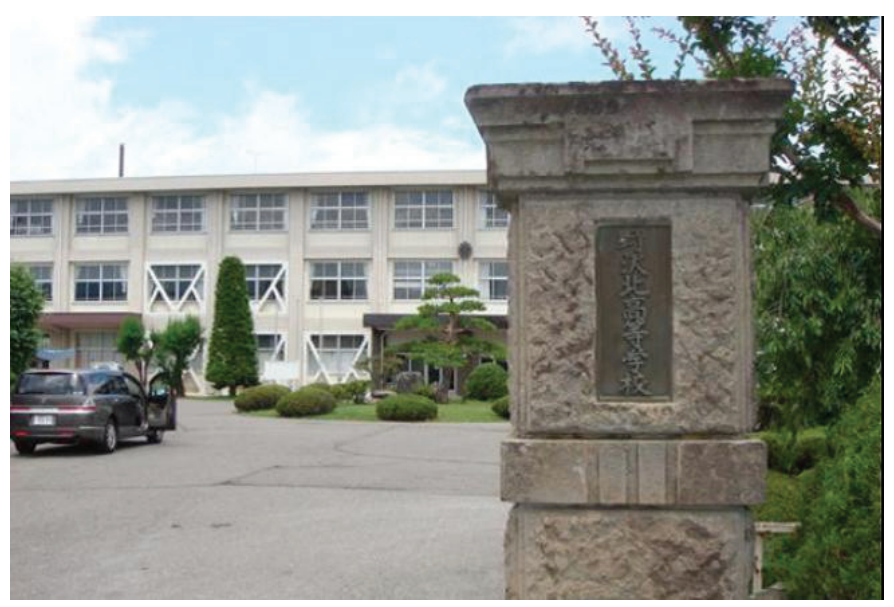

Nozawa Middle School, which Shoshichi attended, is now Nozawa-Kita High School.

blowing clouds of dust, allegedly to "construct the Imperial Headquarters underground of Matsushiro."

At Nozawa Middle School in 1944 when I entered, the school principal, Mr. Shigesaburo Matsuoka was a foremost militant in the prefecture. At the morning assembly

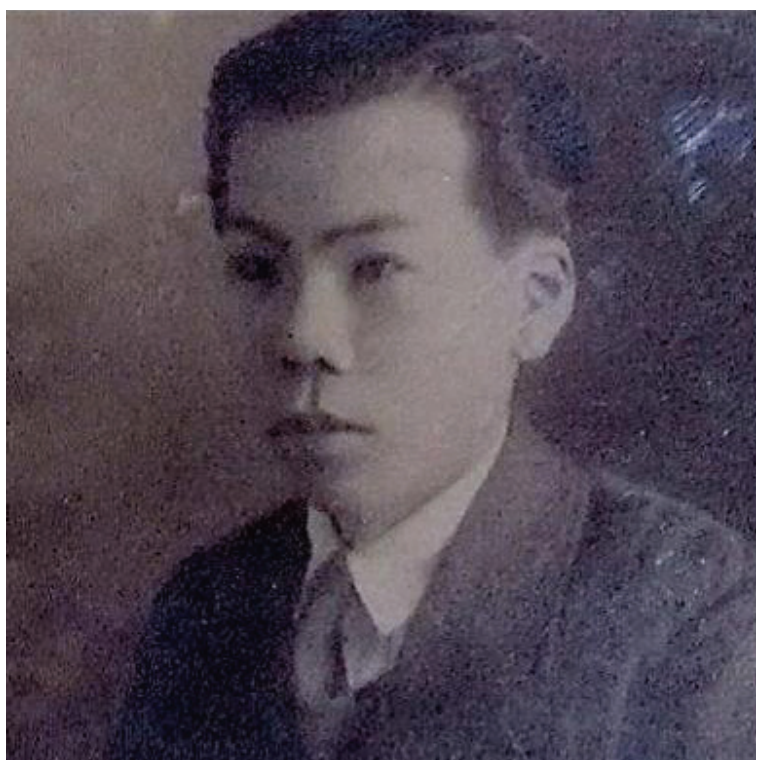

Muneo Hayashi, Shoshichi's mathematics teacher

of the entire school held weekly, he lectured "Great Cause" authored by Lieutenant Colonel Goro Sugimoto, standing on the platform placed in front of the auditorium between two large calligraphy frames hung on the wall, one carrying the character "Chu (or Loyalty)" and the other "Gi (or Righteousness)" drawn in black ink. He de- livered such an impassioned speech that he reportedly left deep scars of his finger-nails on the platform desk. Before taking lunch, the student recited, following the teacher's recitation of the school motto that was extracted from the aforementioned book, saying "We are Emperor's thighs and arms (meaning trusty followers)", followed by the Three Promises: "First, we discharge our duty as sons," "Second, at school, we discharge our duty as students, and Third, we protect our Emperor by serving as his humble shields." Then we said "Itadakimasu!" (meaning "Thank you for this meal") and ate lunch. One day, a teacher reportedly recited by mistake, "Emperor is our thighs and arms!" He turned pale, and immediately returned to the teachers' room, and did not take lunch.

Principal Matsuoka strongly encouraged the students to become "preparatory course trainees" or work for other military organizations, and spurred the students and staff

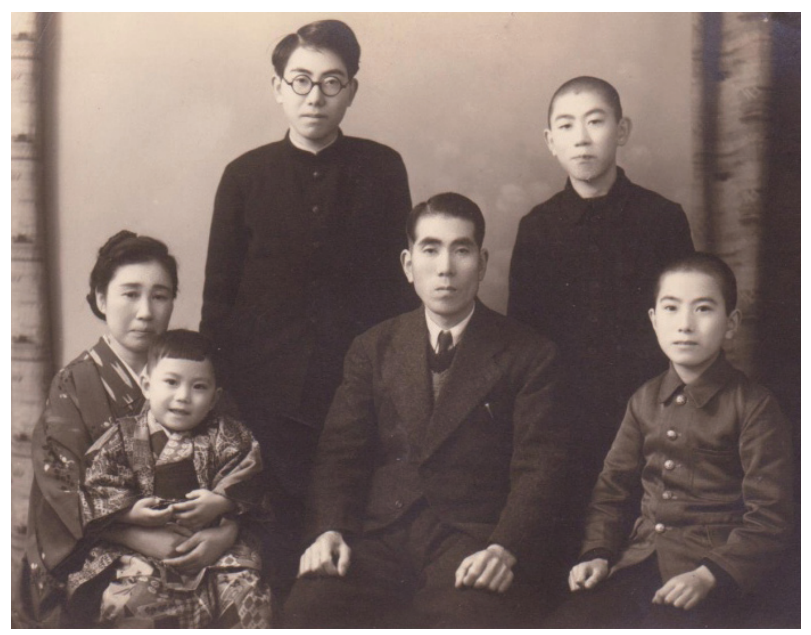

A family photo taken on January 8, 1950, soon after Shoshichi's turned 18. He was a 1st year student at the University of Tokyo. Front row, from left: Mother Yoshie (41), 5th son Kazuo (2), Father Kyuzo (45) and 3rd son Hisashi (11). Rear row: 1st son Shoshichi (18), 2nd son Toshinori (15)

by saying, "Should we lose this war, you must commit Seppuku." He promoted a gymnastic teacher to Vice-principal who gave us completely militaristic training with a military officer commissioned to the School.

\section{Shoshichi at Middle School; the War Ended}

In May 1945 Shoshichi transferred to Nozawa Middle School, which was in the middle of the harsh condition as described above. The 2nd year, the 3rd class (called the second infantry company, the third platoon), into which Shoshichi enrolled, was crowded by far more than fifty students, which was the official capacity of a class. Many students who evacuated to the area were enrolled. So it was difficult for the teacher to check individual students' behavior by walking between desks. Among those evacuee students who came to ask for help of their relatives in the 
region was a son of Admiral Ryusaku Yanagimoto, Captain of the aircraft carrier "Soryu" in the Imperial Japanese Navy, who had died in flames on the bridge of the sinking carrier, hit by a bomb in the Battle of Midway. Another evacuee was a son of the Master Artist Togyu Okumura who was a prominent figure of the Japanese painters circle.

During the period of one and a half year, from April 1944 until the end of the War, there were 186 evacuee students in total (while the nominal capacity was 600), i.e., 15 evacuees per class on average (nominal capacity of 50 per class).

But upper-class students were mobilized for volunteer labor services and were routinely out of the School. In addition to these evacuee students, the machine tools of a factory plant and Army's flight food research lab occupied lecture rooms, research labs and experiment rooms.

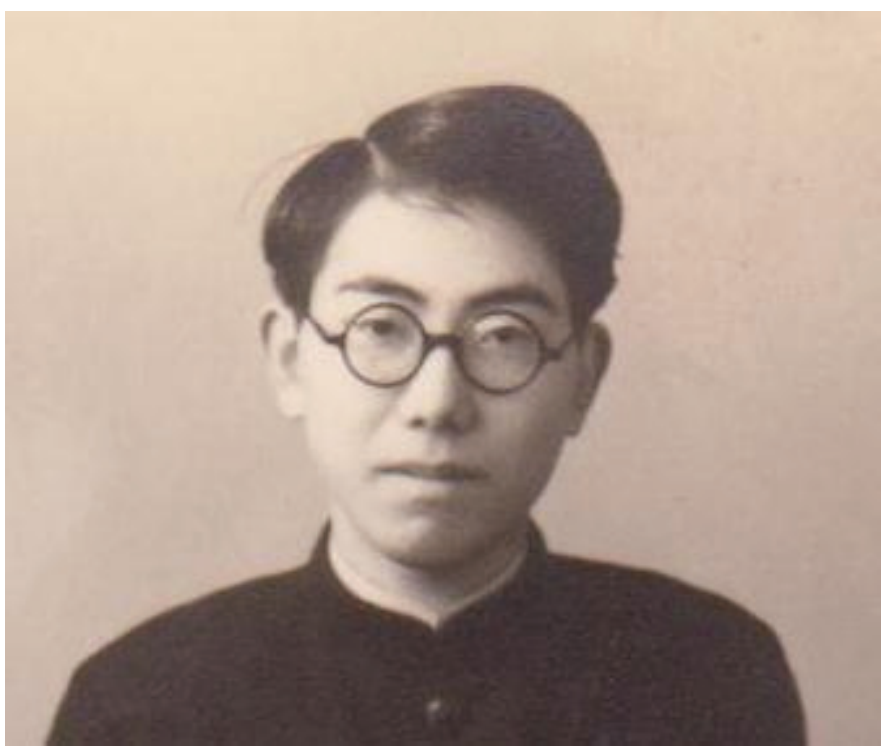

A photograph taken on January 8, 1950, soon after Shoshichi turned 18. He was a first-year student at the University of Tokyo.

Many fifth year students who were recruited to work in munitions factories were among the victims to air raids by B29 bombing fighters. One 4th year student died of electric shock in the Tonankai Earthquake of 1944 (of magnitude 7.0). Many suffered from execrable food situation at the places they served.

Communications between the School and the families of upper-class students who were working in labor services were taken care of by the lower-class students who were still at the School. When the name of an upper-class student was announced at the School assembly, students who lived near his house were supposed to raise their hands and one of them took a letter from the School to the family. In the academic year 1944 (April 1944-March 1945), the sports meeting and other events were not held, and by 1945 the School's ground was reclaimed as agricultural fields to cultivate vegetables and as sites for underground shelters. At the commencement of March 1945 , the 4th year students graduated together with the 5 th year students. At that commencement, neither the song "Hotaru-no-Hikari" (By the Glow of Fireflies) nor "Aoega-Totoshi" (With an Eternally Grateful Heart") was sung, but instead "Gakuto-Shutsujin-no-Uta" (Song for the students who depart for the front) was reportedly sung, but I cannot recall it for sure. It was decided in March 1945 that no classes would be given for a year, and all

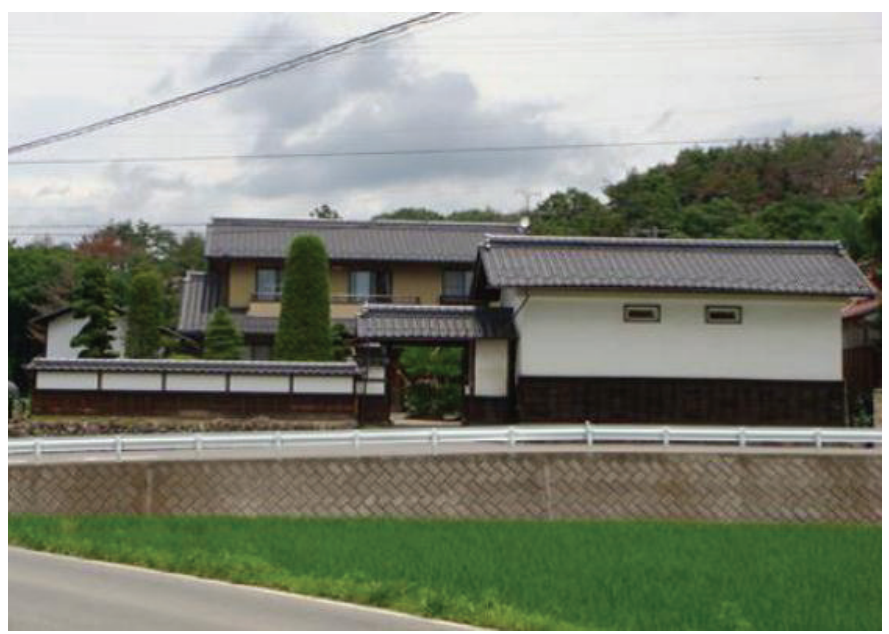

The house of the late Mr. Kinjiro Yanagisawa, where the Kobayashi family stayed in 1945 (the photo by courtesy of Mr. Nobuyoshi Yanagisawa)

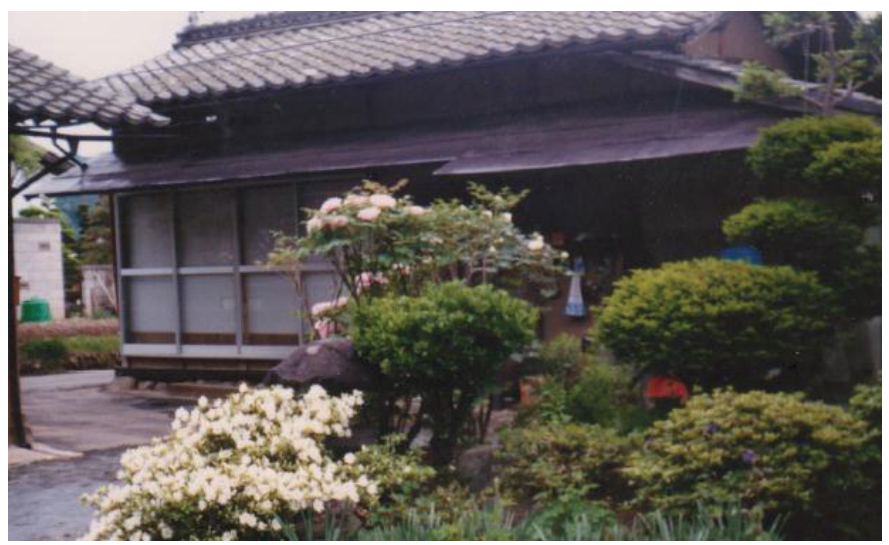

The detached house on the late Mr. Kesazo Yanagisawa's premise, where the Kobayashi family stayed in 1947-48 (the photo by courtesy of Mrs. Kiyoko Yamakawa)

students were obligated to join volunteer labor services or student corps and get trained ready for a Mainland Battle. Thus, the educational functions were at a complete standstill. In the academic year 1945 there were no 5th year students, thus the 4 th year students were the most senior. But most of the 3rd and 4th year students were mobilized to labor forces, being seldom found at the School. The remaining 1st and 2nd year students were divided into groups, and dug underground shelters, did labor services for farmers, and prepared the sites for a 
factory that was coming to evacuate from Tsugami. Thus there were no classes given.

I was assigned to work for the site preparation for Tsugami Plant, which was to be constructed on the west side of North-Nakagomi Station. I used a shovel to cut through clods which were as tall as cliffs and had to flatten them. We worked naked above the waist under the blazing sun. On another day, a student of Minami-Saku Agriculture School (the present Usuda High School) was

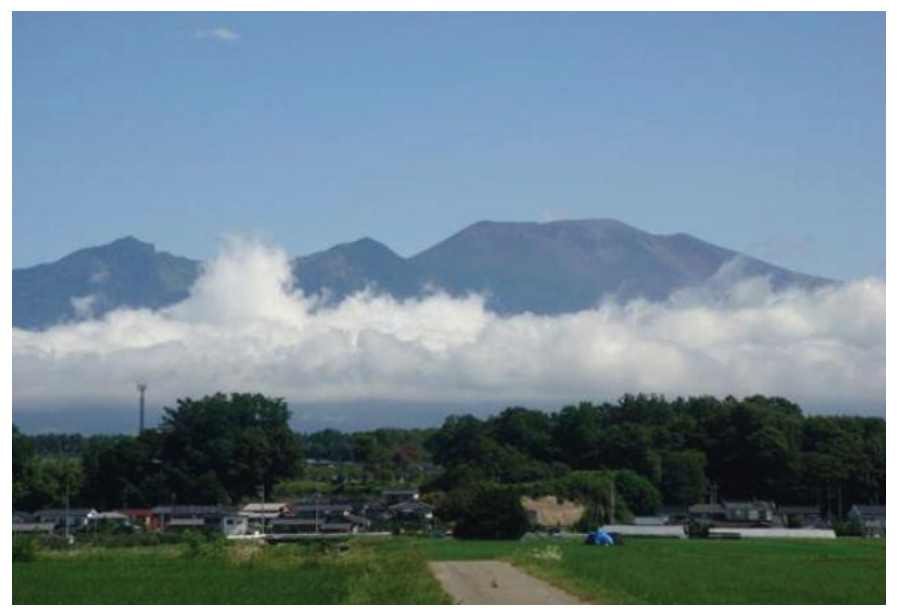

Mt. Asama viewed from Hiraga, Saku, July 2013 by Mr. Nobuyoshi Yanagisawa)

buried under a lump of soil that crumbled down. I did not have any chance to work with Shoshichi during this period. I suppose that he, having just transferred to the School, was watching these incidents quietly in the unfamiliar environment that was so different from those of his middle schools in Tokyo and Kofu.

In August a new type of bombs (i.e., atomic bombs) were dropped on Hiroshima, and Nagasaki, and on August 13th, the first day of "O-Bon" (Lantern Festival to commemorate the Dead) a small-scale air-raid hit Nagano-City, which was said to be a precursor of a fullfledged bombing. On August 15th we listened to Emperor's voice over radio broadcast. The radio signal was rather noisy due to interference. Emperor's voice was heard intermittently and it was difficult to understand the contents of his announcement, but we could figure out that most likely we lost the war. One student dashed into a classroom, shouting "Principal should commit Harakiri!" Principal Matsuoka, who was one of the foremost militaristic principals in the prefecture, encouraging the students to apply for "Preparatory course trainees" and other military organizations, and repeatedly spurred his students and staff by saying, "Should we lose this war, you must commit Seppuku for Emperor!" began to speak for democracy. The irritation of those students who returned to the School after having served the nation as preparatory trainees, strongly urged by the Principal as well as the anger of the teachers and staff found vent in the Principal who started whistling a different tune. They denounced him, by shouting "Principal; you should commit Harakiri and die!" He was replaced in December, being "chased after with a whip," so to speak.

As a new principal of the School, Mr. Mutsujiro Nakazawa was appointed. He was born and raised in Hiraga Village, graduated from Hiroshima Higher Normal School (a public school which trained male teachers), taught mathematics and was a principal of another middle school. He urged us to "throw away hesitation and concentrate on your study." He later got promoted to Chairman of the Prefectural Board of Education. Even after the War, shortage of food was so severe that teachers who came from other parts of the country had a very difficult time in acquiring food, and were much dependent on vegetables grown in the reclaimed fields of the School. I imagine that Shoshichi's family also experienced inconveniences in both food and housing during that difficult period. The evacuee students began to return to their home towns, but I still wonder even today what happened to those who returned to the independent Korea which then entered the Korean War. After the fall of 1945 the school gradually returned to the normal condition and resumed classes. But some teachers who came back home for teaching because they could not find food elsewhere, gave lectures on their own paces, disregarding the academic levels of students, and many students suffered consequently. But a majority of these teachers retired after a short while.

\section{Shoshichi's Encounter with Mr. Muneo Hayashi}

In mathematics course, "permutations and combinations" were added to the curriculum. These topics were not in the old textbook of algebra and geometry used by my elder brother who graduated Middle School in 1941. But the level of mathematics in our class was such that if you remembered the solution formula for a quadratic equation, you could get a perfect score in the exam. So Shoshichi looked bored, looking at the blackboard with his chin on his hand. In March 1946, no commencement took place, because there were no 5 th year students. By the time we became 3rd year students (April 1946-March 1947), the chaotic condition of the postwar had gradually subsided and we finally resumed an environment that allowed us to concentrate on study.

In August 1945, Mr, Muneo Hayashi was hired as a mathematics teacher. He graduated from Tokyo School of Physics (the predecessor of Tokyo University of Science) with a mathematics major. I believe his appointment was a strong desire of Principal Nakazawa. It was rumored among the students that Mr. Hayashi who just finished his graduate study at Nagoya University was a novice in teaching but seemed enjoying in teaching. In the first week after the summer recess of 1947 started, he gave special lectures of five days to 20 students who wanted to take this class. I recall the subjects were primarily fundamentals of differentiation and integration. He also 
served as an advisor for Mathematics Club of upper-classes (4th and 5th years) and taught the subjects on numbers, quantity and spaces, separate from the traditional emphasis on theory and calculations. In 1947 more than 100 students were enrolled, including lower-class students who studied application problems. As for myself, I liked physics and joined Physical Phenomena Club, as well as Gymnastics Club, admiring the elegant style of the preparatory-departments students.

Needless to say, Shoshichi was a member of the Math Club, and at the cultural festival in the fall, he presented "On computation of the effective (root-mean-square)

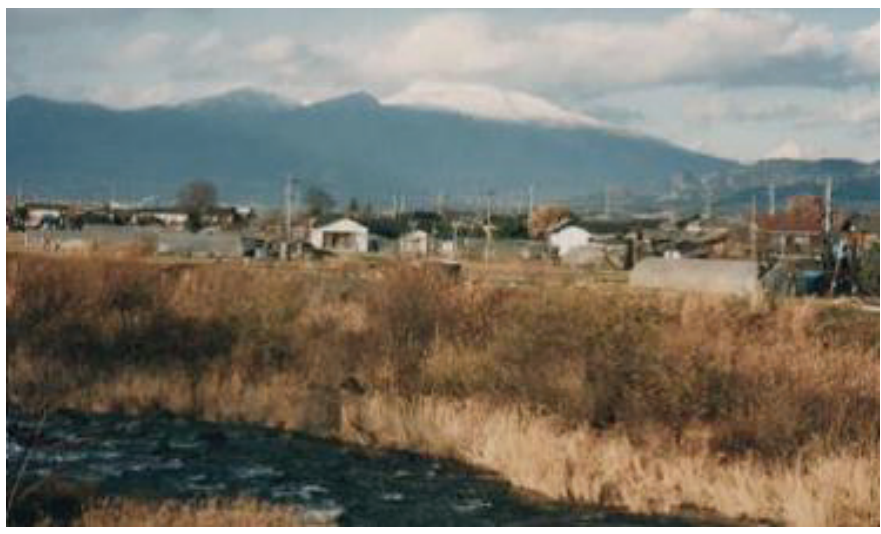

Mt. Asama capped with snow, 1995.

"Capped with the first snow, Mt. Asama becomes a holy mountain." - Haiku composed by Noboru Naito, translated by Hisashi Kobayashi.

(Photograph courtesy of Mr. Masayoshi Yanagisawa.)

value of an alternate current." Although I did not have a chance to listen to his presentation, the "effective value of an alternate current" was a topic related to the integration operator, which I later learned in a required course "Theory of Alternate Current" in my second year at college in 1951. Shoshichi had excellent records not only in mathematics but in all subjects, so the teachers paid attention to his extraordinary talents. One day Shoshichi told me, "Find a way to trisect a given angle, using only a straightedge and a compass." I worked hard on this problem by trial and error. He was grinning by observing that I was still struggling next day on the problem before the morning assembly began. Noticing that I looked troubled even after the morning assembly, he said "It has been proven that this problem is not solvable."

Sometime after the War ended, Shoshichi caught a cold and was absent from the School for many days. Then our homeroom teacher Mr. Tsuneo Yanagisawa (physics) told me "Shoshichi's home is not far from yours. Please go to check up on him." So I visited his house for the first time. He looked better than I had expected and came out to the entrance door, and showed me a book, saying "I am reading this stuff." By seeing that the terms "probability and statistics" on the book, I was impressed to find that he was studying such a book even when he was absent from school. I met his mother but I cannot recall her face.
"Shoshichi's mother is a person of fine character" is what we heard from the villagers who knew the family.

In the 1946 academic year, the athletic meet was resumed. Since the school had a 25 meter swimming pool (which was rare among schools in the Prefecture) at the south-west corner of the ground, it had been a tradition and mandatory for all students to participate in what is called "swimming exercise," all naked except for their loincloths. I did not like this event since I was extremely skinny. In the "centipede race" (in which a team of six students ran on a line with each person's right (left) foot is tied with the right (left) legs of the person in front of and behind him), Shoshichi took the first position in his team. It was a tough role, because he had to withstand the strong push coming from the five students behind him, who hang to the shoulder of the person in front, keeping in steps and shouting in unison "One-two! One-two!" I still vividly recall Shoshichi's fierce face in his desperate effort to run forward, but bending his upper body backward. I admired him for having successfully fulfilled the tough role of the front position.

\section{Aspiring to Become a Mathematician}

Shoshichi found mathematics interesting because of Mr. Hayashi's lecture. Whenever there was any doubtful point, he did not hesitate in asking questions directly to the teacher until he was thoroughly convinced. I envied his courageous attitude, compared with my timid and reticent character. Shoshichi loved the lecture by Mr. Hayashi and accelerated his interest in mathematics, which led to his decision to become a mathematician, as he wrote in various essays.

In March 1948 Shoshichi successfully passed the entrance exam of the First Higher School after finishing the fourth-year at Nozawa Middle School. In April Mr. Hayashi left Nozawa Middle School to take a position at Ueda Middle School, and Shoshichi also left Nozawa to head for Tokyo, which turned out to be his departure to expand his activities to the world as a great mathematician (Shoshichi's family returned to Tokyo in the fall of the same year). When the journal "Mathematical Seminar" was launched by Nihon Hyoron Publisher, Shoshichi contributed articles periodically from abroad where he was studying, partly because Professor Kentaro Yano, his advisor at Todai, was on the editorial board of the journal. So I was following his activities through the journal and was wishing him the best from behind the scenes. To me Shoshichi was already "high above the sky."

Mr. Hayashi, whom Shoshichi admired as "the great teacher whom I owe for having awakened my deep interest in mathematics and for my decision to pursue mathematical research," after having taught a year and eight months at Nozawa Middle School, transferred to Ueda Middle School in April 1948, where he got married and changed his family name to Kurimoto. Under the new education system the middle school became Ueda-Matsuo 
High School (now called Ueda Higher School). Then Mr. Kurimoto moved to a women's high school, Ueda-Someyaoka High School, from which he later retired and passed away in February 2003, on his 79th birthday.

Shoshichi attended the mathematical seminars several times that were held at Sugadaira, which is to the east of Ueda-City, and met Mr. Hayashi three times. In the fall of 2010, after the seminar at Sugadaira, Shoshichi reportedly took a sentimental journey by taking trains that connect Ueda, Komoro, Nakagomi, Kobuchizawa and to Tokyo, and enjoyed the nostalgic scenery from train windows, for the first time in 62 years. If I knew his schedule in advance, I could have asked him to get off at Nakagomi-station and visit the village he stayed and No-

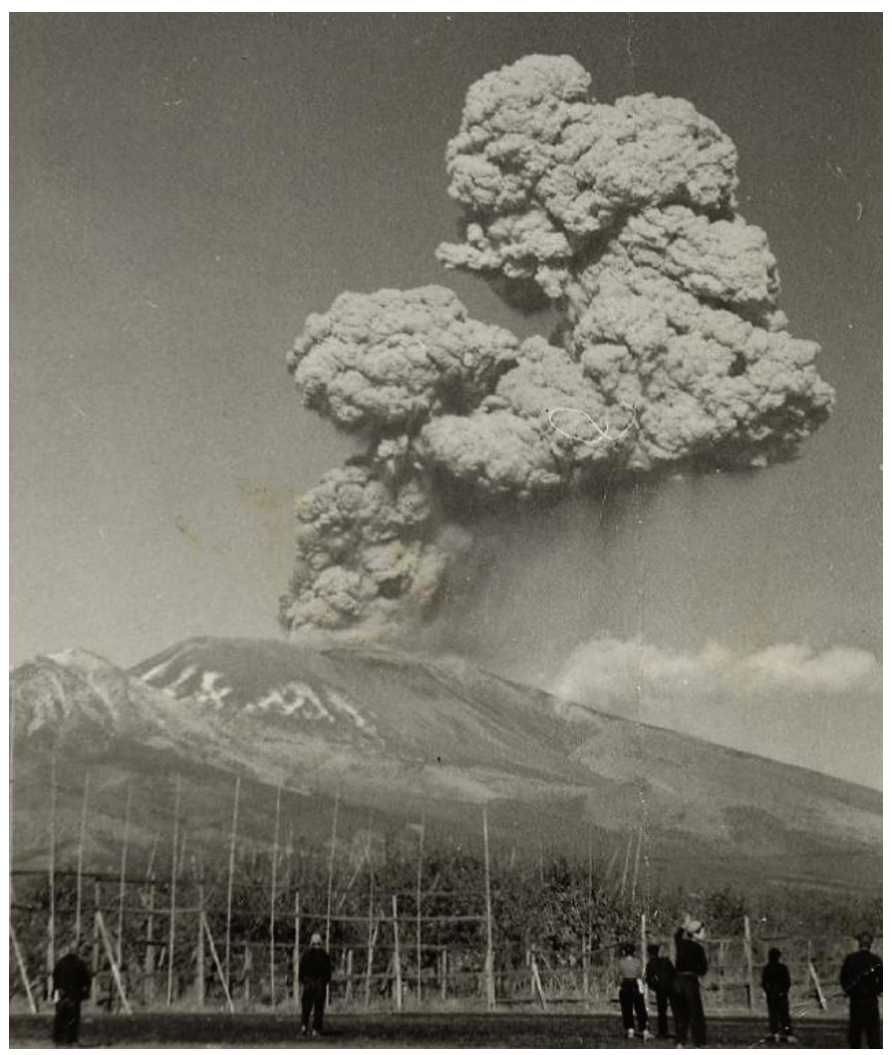

Erupting Mt. Asama viewed from Hiraga, Saku in November 1973 (by courtesy of Mr. Masayoshi Yanagisawa).

zawa-Kita High School. I sincerely regret that I could not do so.

I, being an engineer, have been using mathematics as a tool, without understanding its profound meaning. Shoshichi's work in differential geometry, such as complex manifolds, pseudo distance, hyperbolicity, complex projective spaces, etc. is beyond my head. But I would like to try to understand his book "Differential Geometry of Curves and Curvatures," a revised edition published by Shokabo Press, which has been hoarded at my hand. I had been hoping all along that someday I should invite Shoshichi, asking him to give a lecture on "beauty of mathematics" to the students at Nozawa-Kita High School, but the sad news of his demise came before I could ar- range it. I feel very sorry for both Shoshichi and our alma mater.

\section{Conclusion}

I would like to express my profound respect for his immortal accomplishments in mathematics and my heartfelt condolence to the family. May his soul rest in peace. 